\title{
SOCIETY NEWS
}

\section{MRS reports election results for 2022}

mrs.org/about-mrs/governance

$\mathrm{M}$ embers of the Materials Research Society (MRS) have elected a vice president (who will serve as president in 2023) and four directors to join the 2022 MRS Board of Directors. Furthermore, a proposed change to Article III of the MRS Bylaws to change the MRS Treasurer's term to be three years, consistent with the terms for all other MRS Board Officers, was passed.

The MRS Board of Directors is the highest governing body of MRS, responsible for establishing policy, monitoring progress of the Society toward its long-term goals, and setting the strategic directions for the activities of the Society, including its meetings, publications, interactions with government agencies, and cooperative efforts with other professional societies.

It is composed of the officers of the Society and 12 to 21 directors, 25\% of whom may be appointed. The exact number shall be set by resolution of the Board of Directors.

MRS directors are elected for threeyear terms. The president-elect serves three years (as president-elect, president, and past president); the secretary is elected for a three-year term; and now the treasurer will also be elected for a three-year term. Members of the Board may serve on one of the Board's committees (Executive, Finance and Audit, or Governance), Board task forces, or other ad hoc efforts commissioned by the Board.
Terms of office expire at the end of the year indicated in parentheses. The asterisk $(*)$ designates those who are newly elected. The annual election ended August 26, 2021.
President

Carolyn R. Duran

Intel Corporation

Immediate Past President

Cherie R. Kagan

University of Pennsylvania

Vice President (President-Elect)

* Sabrina Sartori

University of Oslo
Secretary

Dawnielle Farrar-Gaines

Johns Hopkins University

Treasurer

Shenda Baker

Synedgen Inc.

Executive Director

Todd M. Osman

Materials Research Society

*Newly elected.

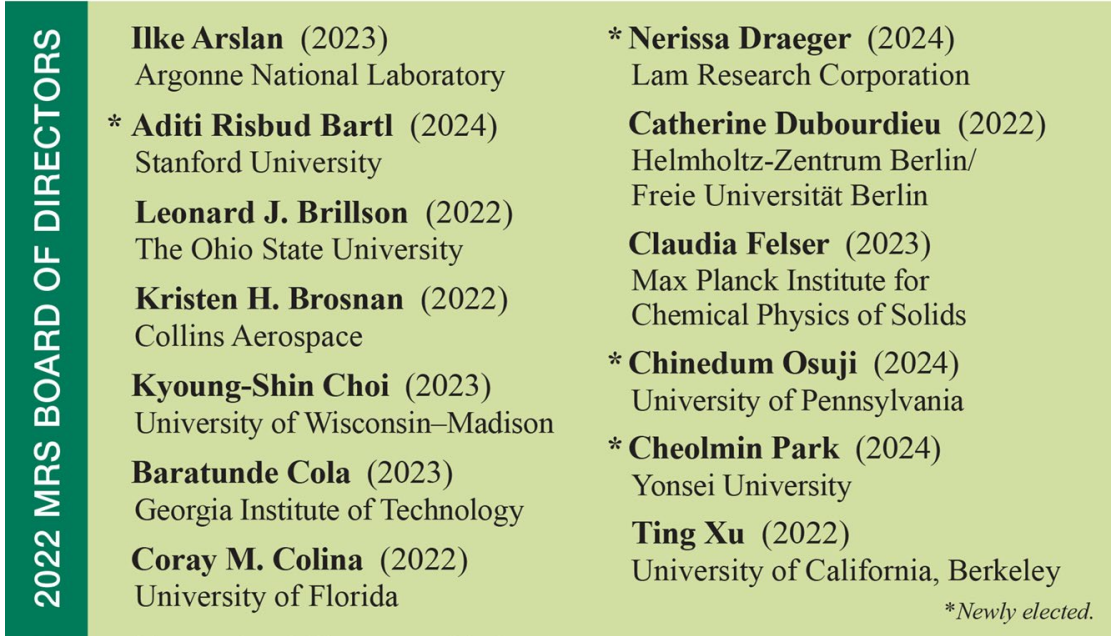

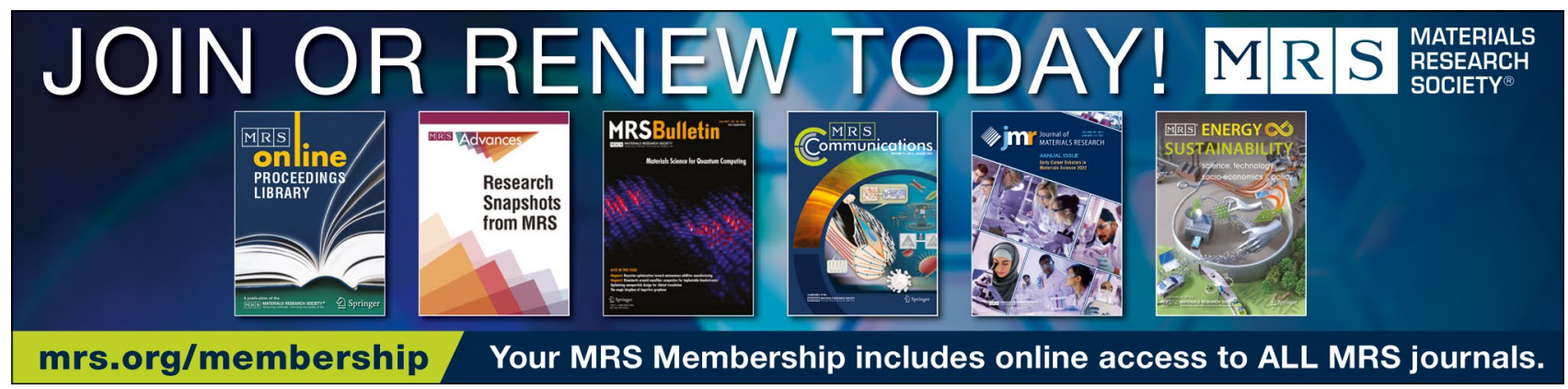

